- Revista de Iniciação à Docência, v. 5, n. 1, 2020 -

Dossiê Temático: Docência Universitária: contribuições da pesquisa Publicação: maio, 2020 - ISSN 2525-4332

\title{
A CONDIÇÃO DA DOCÊNCIA UNIVERSITÁRIA NO CONTEXTO ATUAL DAS UNIVERSIDADES: MARCAS HISTÓRICAS, REALIDADE E PERSPECTIVAS
}

Talamira Taita Rodrigues Brito ${ }^{1}$ Beatriz Salemme Correa Cortela ${ }^{2}$

RESUMO: O artigo tem como objetivo refletir sobre alguns aspectos teóricos acerca da condição da docência e dos docentes universitários, seus saberes, seu trabalho e as relações construídas historicamente com esse fazer. Apresentamos um percurso da consolidação do ideário da universidade pública brasileira e os desdobramentos na costura da docência universitária como condição diferenciada para se realizar o trabalho, entendido por nós como sendo o ambiente de desenvolver-se profissionalmente, ao mesmo tempo em que é o lócus provocador de mudança da própria universidade, da própria condição docente e de sua relação com a sociedade. $O$ projeto inacabado de universidade pública brasileira está sujeito, mais uma vez, ao enfrentamento da lógica do neoliberalismo, de aligeirar-se, despir-se de tempo para conhecimento, para produção, para qualidade do fazer pedagógico, na medida que sua pouca autonomia conquistada começa a ser retirada através do falso discurso da não ou da baixa produtividade a serviço do mercado e das demandas do capital não atendidas. $O$ impacto dessas ameaças está diretamente ligado à conformação que a docência assume e submete-se para tentar sobreviver. Professores cansados, desanimados, produzindo, muitas vezes, trabalhos com qualidade duvidosa e submetendo-se às péssimas condições de trabalho, salários que não correspondem com a condição e exigência da profissão, ou, ainda, editais que nem sempre aportam recursos que validem um montante significativo de financiamento para pesquisa e ou para o aumento no número de pesquisadores, põem a mostra da realidade atual, que carece de mudanças conceituais sobre o que é a universidade e de suas condições para construir a docência universitária.

Palavra-Chave: Docência Universitária; Função Social da Universidade; Identidade Docente.

\section{Introdução}

"... e o coelho dizia para si mesmo: Meu deus, meu deus!!!

Como estou atrasado!"

Lewis Carroll (1865)

O tema deste dossiê nos leva a refletir sobre diversos aspectos relativos à docência universitária: o lócus e o tempo do trabalho deste profissional, os modelos organizacionais e a função social da universidade (SOUZA et al., 2013); sobre as diferentes funções que este profissional é chamado a desempenhar, ligadas ao ensino, à pesquisa, à extensão, à gestão, ao business (ZABALZA, 2005); sobre seus saberes (TARDIF, 2002); seu campo de atuação e sua identidade profissional

\footnotetext{
${ }^{1}$ Doutora em Educação (UFU). Professora do Programa de Pós-Graduação em Educação Científica e Formação de Professores, Universidade Estadual do Sudoeste da Bahia, Jequié/BA. Contato: taitadoc@gmail.com

${ }^{2}$ Doutora em Educação para Ciências (UNESP - Bauru). Professora do Programa de Pós-Graduação em Educação para as Ciências, Universidade Estadual Paulista - Faculdade de Ciências, Campus de Bauru/SP. Contato: beatriz.cortela@unesp.br
} 
- Revista de Iniciação à Docência, v. 5, n. 1, 2020 -

Dossiê Temático: Docência Universitária: contribuições da pesquisa Publicação: maio, 2020 - ISSN 2525-4332

(GARCIA, 2009); a produtividade e precarização do trabalho (SGUISSARDI; SILVA JR, 2009), entre outros temas que são recorrentes como uma necessidade ainda do campo, que consideramos em expansão.

Também nos chama a atenção o contexto brasileiro que estamos vivendo, quando são nítidas as tentativas de desmanche das instituições públicas de ensino superior em decorrência não somente dos cortes de verbas e financiamentos, mas numa clara intenção de desqualificar a pesquisa nacional, tanto considerando seus resultados, quanto seus propositores. A universidade pública como um bem público está abalada, o pensamento privatista (CASTANHO, 2000) passa a fazer parte de seu cenário na tentativa de transformar tudo que realizamos em um produto e/ou serviço à disposição dos que podem pagar.

Além disso, o modelo de administração neoliberal, com foco na produtividade, no menor custo - maior benefício em menos tempo, impõe a construção de um tempo de produção que é inversamente proporcional ao tempo do conhecimento construído à luz de pesquisas, com seus tempos e necessidades próprias. Tempo, fator que a todos nós parece estar consumindo, ditando o ritmo do trabalho e levando nossas atividades, de teor intelectual e que demandam reflexão para reelaboração, na direção de uma produtividade, de qualidade, muitas vezes, duvidosa. Fazendo uma alusão ao o coelho branco de Alice no País das Maravilhas, estamos sempre correndo e atrasados. É o deus Cronos, senhor do tempo, a devorar seus filhos.

Nesse contexto, pensar na docência, em especial aquela desenvolvida nas universidades, para além de fazer todo sentido para nós, pesquisadoras da área, configura-se como um ato político e de resistência. É necessário deixar em evidência o trabalho de um grupo de profissionais que realiza a maior parte das pesquisas do país, que faz atendimentos em áreas diversas por meio de suas atividades práticas e extensionistas, e que forma novos profissionais com qualidade há exatamente um século, profissionais estes para as mais diversas áreas da/para a sociedade. Essa instituição, nessa relação dialética/dialógica, também aprende, se questiona e, no momento atual, resiste para continuar se validando como um patrimônio do povo, a serviço da sociedade, da Ciência, da Tecnologia e da Inovação.

E a docência, ambiente que materializa a relação entre o professor e seus desafios de produzir conhecimento em sala de aula, em laboratório de estudo e pesquisa e nas atividades de extensão, sempre fora desafiada como um lugar de fácil acesso e fácil fazer, muitas vezes reduzida à ação de dar aulas, que pode remeter a um sentido diverso daquele que consideramos ser, o ministrar aulas, ou seja, colocar

\footnotetext{
${ }^{3}$ Obra cujo autor é Charles Lutwidge Dodgson, sob o pseudônimo de Lewis Carroll (1865).
} 
- Revista de Iniciação à Docência, v. 5, n. 1, 2020 -

Dossiê Temático: Docência Universitária: contribuições da pesquisa Publicação: maio, 2020 - ISSN 2525-4332

ao alcance dos estudantes os conhecimentos. Como se isso não nos exigisse maiores esforços e/ou maiores saberes para sua elaboração (BRITO, 2006).

Por sua vez, reconhecemos que são muitas as variáveis que envolvem a profissão de docente universitário e a docência. Neste artigo fazemos algumas reflexões teóricas acerca dos docentes universitários, seus saberes, seu trabalho e suas relações construídas historicamente com esse fazer.

Para tanto, fora feito um esforço de refletir sobre os modelos de universidade que inspiraram o Brasil republicano em sua dinâmica de consolidar essa instituição e seus efeitos, no olhar para o professor universitário. Ainda aqui fizemos um esforço de apresentar os quatro modelos de universidades predominantes no Brasil, com suas-variações híbridas, com a intenção de refletir sobre como tais modelos nos ajudaram a compreender sua função social e, por consequência, as atividades que foram e passaram a ser mais valorizadas nos diversos ambientes e instituições dessa natureza.

A universidade é um tipo de organização complexa, que apresenta um modelo de gestão muito particular e híbrido, que mescla características de uma burocracia mecanizada com as de uma burocracia profissional (MINTZBERG, 2003). Grande parte dos desafios e dilemas enfrentados pela universidade advém exatamente deste hibridismo (SOUZA et al., 2013, p. 218)

Num segundo momento, discutimos sobre a docência, os saberes necessários ao docente universitário e os compromissos sociais da profissão. Por fim, apresentamos algumas conclusões desse exercício de pensar sobre a nossa condição de docente universitário no atual contexto, a realidade que nos é apresentada e quais perspectivas para continuar na luta por maior reconhecimento institucional e valorização de nosso trabalho.

\section{Reflexões sobre a função social da universidade ${ }^{4}$ - lócus de trabalho do docente universitário}

Fazer um esforço de refletir sobre os modelos que inspiraram o Brasil na consolidação de seu pensar e construir universidade se faz necessário visando entender que noção de docência foi sendo desenvolvida e quais os desafios, construídos ao longo do século $X X$, se refletem diretamente na (des)valorização do trabalho do professor universitário e, por sua vez, na docência universitária.

Outro aspecto que se reflete em tal entendimento está associado à construção de sua função social, ainda não consolidada no imaginário social e na própria estruturação das políticas públicas federal e estaduais, já que até a presente data não se chegou ao entendimento pacificado da relação entre república/democracia/ universidade pública/ autonomia/produção de conhecimento/

\footnotetext{
${ }^{4}$ As autoras fizeram uma escolha em focar na realidade das universidades públicas.
} 
- Revista de Iniciação à Docência, v. 5, n. 1, 2020 -

Dossiê Temático: Docência Universitária: contribuições da pesquisa Publicação: maio, 2020 - ISSN 2525-4332

investimento público/ acesso e permanência de pessoas/gratuidade de acesso, num país como o Brasil, de economia instável e de baixo rendimento de escolarização em seus variados níveis.

Segundo o resultado do Censo da Educação Superior 2019, somos um país cujas pessoas, em sua maioria, possuem uma média de 9,5 anos de escolarização em relação aos desejados 14 anos da educação básica; a maioria das pessoas não atinge ou ainda não conclui o ensino médio; e que chegar ao ensino superior na faixa dos 18 aos $24^{5}$ anos ainda é uma meta a ser perseguida, de acordo com o Plano Nacional de Educação. Poucos alunos avançam em direção ao ensino superior e, quando isso acontece, a esmagadora maioria procura a rede privada (turno noturno) na tentativa de ter seu diploma, por ser de fácil acesso, na maioria dos cursos.

O censo ainda aponta que ao logo dos últimos anos tivemos redução no número de matrículas nas instituições públicas e avanço significativo nas instituições privadas, também em decorrência do Fundo de Financiamento Estudantil (FIES), um programa criado pelo Ministério da Educação (MEC) em 2004 para oferecer financiamento estudantil aos estudantes de cursos de graduação de instituições privadas e que objetiva facilitar o acesso de jovens de baixa renda à educação superior. Trata-se de um financiamento público para a iniciativa privada, uma vez que a instituição de ensino recebe pelo serviço prestado e o aluno, se quitar as parcelas do financiamento, restitui ao Estado esse empréstimo. Quando isso não ocorre, o Estado acaba financiando a iniciativa privada, um embate presente na educação pública desde a aprovação de Lei de Diretrizes e Bases (Lei n. 4024/61). De acordo com Cunha e Goes (2002), esta LDB acabou sendo uma conciliação entre dois interesses: propiciou algumas vantagens para os setores conservadores, mas a gratuidade do ensino, que era uma conquista constitucional, ficou sem explicitação, permitindo que o Estado pudesse financiar as escolas privadas (Art. 95).

Compreendemos, para além das afirmações feitas acima, que a sociedade brasileira tem cumprido o feito neoliberal de minimizar a atuação do público e transformar a rede privada em lócus de prestação de serviços de diplomação. Em contrapartida, Teixeira (1999) já nos afirmava que a universidade pública ainda é elitizada, no formato e no pensamento de se fazer presente no comum da vida das

\footnotetext{
${ }^{5}$ Censo da Educação Superior 2018. Notas estatísticas apresentam os seguintes dados sobre oferta de vagas e matrículas: $88,2 \%$ das Instituições de Ensino Superior são privadas. A rede pública (universidades e institutos federais, universidades estaduais e municipais) hoje representam $11,8 \%$, isso é traduzido num total de 2.864 .999 vagas ofertadas pela rede privada contra 580.936 da rede pública. Registra-se uma redução de $1,5 \%$ na oferta de vagas públicas. Isso reafirma a expansão do modelo privatista de ensino superior que o Brasil assumiu como política. Veja-se em:

http://download.inep.gov.br/educacao_superior/censo_superior/documentos/2019/apresentacao_censo_superior2018.pdf http://download.inep.gov.br/educacao_superior/censo_superior/documentos/2019/censo_da_educacao_superior_2018notas_estatisticas.pdf
} 
- Revista de Iniciação à Docência, v. 5, n. 1, 2020 -

Dossiê Temático: Docência Universitária: contribuições da pesquisa Publicação: maio, 2020 - ISSN 2525-4332

pessoas, já que, historicamente, foi pensada para forjar uma elite intelectual para a construção de uma suposta elite política brasileira.

Ainda nesse sentido, é necessário compreender que o princípio que nutriu o Brasil colonizado pelo português ${ }^{6}$ dificultou a construção do pensamento de criação da universidade brasileira, que por decreto foi fundada em $1920^{7}$. Ou seja, 400 anos depois de sua colonização. Isso por temor da coroa de movimentos independentistas ${ }^{8}$. Portanto, tardiamente, após movimentos republicanos de final de século XIX, e tentativas frustradas de criação de universidades entre os anos de 1900 e 1920, a Universidade do Rio de Janeiro chega como realidade, nascida da união das faculdades de Medicina, Engenharia e Direito.

Mas, qual a configuração de época, qual modelo serviu de referência, naquela ocasião? Segundo a literatura especializada, as universidades atuais podem ser compreendidas a partir três modelos clássicos inspiradores do século passado (SOUZA, et al., 2013), sendo que, no final do século XX, um quarto modelo surge nos países europeus e que afetará radicalmente o sentido, a política pública de financiamento e manutenção de nossas instituições como a conhecemos (ARAÚJO; SILVA; DURÃES, 2017).

O primeiro deles, conhecido como napoleônico por ter sido institucionalizado na França, em 1806, consiste em um modelo com perspectiva funcionalista, tendo por função social, além da produção de conhecimento, a formação das pessoas para o trabalho e as profissões na sociedade liberal de época. Neste modelo, há uma segmentação entre as instâncias que promovem o ensino e as que promovem a pesquisa, de maneira que as atividades de ensino possuem primazia - porta de entrada da organização da docência em nossas instituições até meados da década de 1930.

O segundo modelo, conhecido como humboldtiano ou modelo alemão, foi desenvolvido por Wilhelm von Humboldt (1810), adotado pela universidade de Berlin e demais instituições alemãs, consiste em um modelo com maior autonomia de gestão das universidades em relação a instâncias externas, tais como o Estado, a

\footnotetext{
${ }^{6}$ Uma observação necessária: Portugal, ao contrário de vários países vizinhos, em especial a Espanha, não tinha um sistema de universidade desenvolvido à época de nossa colonização - as universidades de Évora e Coimbra eram as referências.

7 A construção do ensino superior fora dividida em três momentos: estudos superiores (período jesuítico); escolas superiores (século XIX); Universidades (a partir de 1920). Atualmente a universidade convive com outros espaços de oferta de formação superior: faculdades isoladas, faculdades integradas e centros universitários. Os dois primeiros com atividades de ensino ligados à sala de aula. O último para receber tal nomenclatura deverá oferecer atividades de extensão e/ou de pesquisa. Já as universidades são denominadas instituições complexas em sua dinâmica de oferta uma política plena de ensino, pesquisa, extensão conectados em todas áreas de oferta de graduação.
}

${ }^{8}$ Ao contrário da Espanha, que via na universidade uma marca de sua colonização. Ver Fávero (2000). 
- Revista de Iniciação à Docência, v. 5, n. 1, 2020 -

Dossiê Temático: Docência Universitária: contribuições da pesquisa Publicação: maio, 2020 - ISSN 2525-4332

Igreja e os setores privados. Nesse modelo, influenciado pelo positivismo, a pesquisa, e sua consequente produção de conhecimento, corresponde à principal função social da universidade: o livre pensar é marca deste movimento ${ }^{9}$. Essa tendência chega ao Brasil como proposta a partir da década de 1930 e a USP é herdeira desse ideal que, de certa forma, nutre o pensamento brasileiro atualmente.

O terceiro modelo, apresentado ao Brasil pelos Estados Unidos, consiste em ajustar os objetivos da educação superior às demandas da sociedade de consumo, proliferando instituições de ensino superior privadas, ou ainda privatizando por dentro a estrutura das universidades públicas. Marcadamente para Silveira e Biancheti (2016), será

A partir do final da década de 1970 e início de 1980, com a subida ao poder das forças políticas ultraconservadoras na Inglaterra, nos Estados Unidos e na Alemanha - representadas, respectivamente, por Margareth Thatcher, em 1979, Ronald Reagan, em 1980, e Helmut Kohl, em 1982 -, marcadamente neoliberais, as políticas contrarreformistas no campo da educação superior passam a alterar as regras tradicionais de gestão e financiamento universitário. Separam as universidades de ensino daquelas de pesquisa, promovem a hierarquização do ensino e de instituições com base em processos de avaliação padronizados, além de intervir não só na liberdade acadêmica em nome da "eficiência" e da "produtividade" [...], mas também na autonomia universitária, que passa a ser entendida como atributo de um movimento de aproximação ao setor empresarial (p. 81).

O Brasil iniciará um ciclo longo de consolidação em defesa desse modelo, na medida que os acordos estabelecidos entre Brasil e Estados Unidos se consolidam durante a ditadura militar (Golpe de 1964) e seguem com a Lei da Reforma Universitária (Lei 5540/68) que:

[..] incorpora várias características da concepção universitária norteamericana, a saber: a) vínculo linear entre educação e desenvolvimento econômico, entre educação e mercado de trabalho; b) estímulo às parcerias entre universidade e setor produtivo; $c$ ) instituição do vestibular unificado, do ciclo básico ou primeiro ciclo geral, dos cursos de curta duração, do regime de créditos e matrícula por disciplinas, todas estas medidas visando uma maior racionalização para as universidades; d) fim da cátedra e a instituição do sistema departamental; e) criação da carreira docente aberta e do regime de dedicação exclusiva; f) expansão do ensino superior, através da ampliação do número de vagas nas universidades públicas e da proliferação de instituições privadas, o que provocou uma massificação desse nível de ensino; g) a ideia moderna de extensão universitária; h) ênfase nas dimensões técnica e administrativa do processo de reformulação da educação superior, no sentido da despolitização da mesma (PAULA, 2002, p. 159).

Seguindo esta métrica, atravessamos as décadas de 1970 a 1990 numa tensão entre aquelas universidades que nasceram antes da ditadura militar de 1964, inspiradas nos modelos francês e alemão e as universidades criadas durante o regime

\footnotetext{
9 Paula (2002) registra que a criação da Universidade de São Paulo em 1934 já sofrera influência alemã.
} 
- Revista de Iniciação à Docência, v. 5, n. 1, 2020 -

Dossiê Temático: Docência Universitária: contribuições da pesquisa Publicação: maio, 2020 - ISSN 2525-4332

militar e, posteriormente ao mesmo, numa tentativa de reviver seus formatos originais, na mesma medida que a autonomia, didática e financeira, se tornava uma bandeira de luta nacional, à medida que a reabertura democrática chegava com a Constituição de 1988.

Com apontam Souza et al. (2013), após o período de abertura política, durante a redemocratização, inicia-se no Brasil um novo período histórico, caracterizado pela aproximação com os ideais neoliberais que trazem consigo, nas universidades, um processo de avaliação docente com base na produção acadêmica, com maior peso na pesquisa, mas cobrando também a atividades extensionistas e de ensino.

Esse comportamento pode ser considerado uma das razões para a docência universitária vivenciar oscilações entre a valorização da pesquisa e desvalorização das atividades em sala de aula (o ensino), assim como ainda a não superação das disputas entre áreas que supostamente fazem Ciência (área de Ciências Exatas, por exemplo) e as outras que não fazem (exemplo, a área de Ciências Humanas), reforçando apenas o discurso comum que não ajuda a universidade a enfrentar suas reais disputas internas.

Durante o final da década de 1990, debates ocorridos na Europa culminariam, em 1999, na elaboração de diretrizes para as Instituições de Ensino Superior que ficaram conhecidas como Tratado de Bolonha, o qual vem se configurando como um quarto modelo de universidade e já se faz presente em todos os países da União Europeia (ARAÚJO; SILVA; DURÃES, 2017).

Esse modelo visou unificar os sistemas de ensino superior dos países envolvidos, por meio de um sistema comum de créditos (european credit transfer and accumulations system), facilitando a mobilidade discente e docente, e reduzindo o tempo de formação. Como caraterística principal, a graduação é estruturada para ser concluída em três anos, mais um ano de master e três anos de doutorado, num processo de aligeiramento formativo marcando, de uma vez por todas, a influência do modelo americano para além dos países da América Latina.

Quando voltamos nossos olhares para tais modelos administrativos de universidades e comparamos com o que edificamos aqui no país durante esse primeiro século, percebemos que somos herdeiros das influências dos três modelos iniciais que, na prática, não se efetivaram em sua plenitude.

Muitas vezes atropelada pelos modismos, conveniências e convênios (Brasil e Estados Unidos), a universidade brasileira foi sendo (con)fundida, a mercê muito mais de humores políticos do que das percepções sobre sua função e importância num projeto de desenvolvimento do Estado, do social, da cultura e do conhecimento, constituindo modelos híbridos. 
- Revista de Iniciação à Docência, v. 5, n. 1, 2020 -

Dossiê Temático: Docência Universitária: contribuições da pesquisa Publicação: maio, 2020 - ISSN 2525-4332

Num primeiro momento, teremos a atividade de sala de aula (universidades de ensino) como predominante. Numa segunda fase teremos uma universidade do livre pensar, com foco maior na pesquisa e no saber desinteressado, tentando gozar de uma autonomia financiada pelo Estado (sua grande contradição). Num terceiro momento teremos uma universidade aliada ao desenvolvimento industrial, que fomenta ensino/pesquisa para áreas tecnológicas. Por fim, entre a saída do país da ditadura e o processo de reabertura política, temos um processo de coexistência de tais modelos orbitando em departamentos, faculdades, institutos, sem muitas vezes questionarmos o que de fato queremos como/de/para a universidade brasileira.

Por esta razão afirmarmos que no caso da identidade da universidade pública, compreendemos que estas foram estruturadas em modelos considerados clássicos o napoleônico, o humboldtiano, e o americano, mas não em sua forma pura. Ocorrem hibridismos que se intensificam devido às intenções mais recentes, que visam atender às demandas da internacionalização, a busca por capital externo para produção de conhecimentos e, uma aproximação maior com os interesses da iniciativa privada. Como afirmam Souza et al. (2013) “(...) é que não se encontra uma definição clara que se possa caracterizar, na essência, a universidade brasileira ( $p$. 218).

Tomando essa afirmação como referência, perguntar sobre o trabalho docente do professor universitário e/ou questionar sobre o que é o trabalho dessa categoria profissional, se torna um desafio diário para o campo de investigação e também para a consolidação de um corpo identitário de saberes, práticas que, de certo modo, referendam as posições político-ideológicas no discurso de quem somos e qual o nosso propósito na realização da sociedade almejada.

Consideramos, também, que a identidade docente está diretamente relacionada à função social da universidade à qual está vinculado e ao projeto pedagógico do curso de graduação em que atua. No caso da maioria das universidades particulares, o foco da atuação docente está no ensino, na extensão e na pesquisa, nesta ordem. No caso das instituições públicas, na pesquisa, no ensino e na extensão, nesta ordem. O lócus do trabalho tem influência sobre as atividades desenvolvidas pelos docentes e na constituição de seus saberes. Em ambas as instituições os docentes desempenham as mesmas funções, que são valorizadas em pesos diferentes, mas todos têm que desempenhá-las. Assim, há predominância de traços de individualidade; mesmo nos projetos coletivos, os docentes se agrupam por suas características individuais, baseadas na meritocracia, que tem um enfoque muito forte em suas publicações e levantamento de verbas junto às instituições de fomento.

O campo de estudo sobre a Docência Universitária passa a ganhar fôlego a partir da construção dessa universidade, mas também da vida que passa a coexistir 
- Revista de Iniciação à Docência, v. 5, n. 1, 2020 -

Dossiê Temático: Docência Universitária: contribuições da pesquisa Publicação: maio, 2020 - ISSN 2525-4332

entre os modelos de universidade, entre os valores construídos pelos pares sobre o que é ensinar, exercer a docência, construir uma identidade com a docência, criar políticas de entendimento da classe trabalhadora, edificar um olhar de dentro da instituição sobre quem somos e o que queremos construir como professores das universidades públicas brasileiras.

\section{A docência universitária: um amálgama de saberes, identidade profissional, e condições de trabalho}

Se a universidade brasileira não tem uma essência/modelo administrativo claro, também aqueles que nela atuam como docentes/pesquisadores constroem para si identidades profissionais, não só partir de suas escolhas ideológicas, nas quais se baseiam em função daquilo que acreditam ser a função social da universidade e, por conseguinte, de seu trabalho, mas também a partir de seus saberes e das condições de seu trabalho.

Dentro deste cenário instável, a docência universitária se constitui em um campo de pesquisa interessante. Diversos investigadores têm se dedicado ao tema, a partir de diferentes enfoques. No Brasil, destacam-se Pimenta e Anastasiou (2002), Masetto (2003); Pimenta e Ghedin (2006); no contexto internacional Alarcão (1998), Garcia (1999); Gauthier et al. (1998); Nóvoa (1992), Zabalza, 2004, entre outros.

Concordando com Cunha (1998, p.33), “[...] o professor universitário é o agente principal das decisões no campo [...], é (quem) concretiza a definição pedagógica e, na estrutura acadêmica de poder, representa a maior força”. No entanto, mesmo tendo tanto peso na efetivação de mudanças pretendidas, o trabalho do docente superior não tem sido alvo de pesquisas, conforme apontam alguns autores (ALMEIDA, 2012; CUNHA, 1998; 2006; DELIZOICOV, 2010; GARCIA et al., 2005).

Almeida (2012) define a docência universitária como "[...] conjunto de concepções de natureza pedagógica, psicológica, filosófica, política, ética, epistemológica que articulam a prática educativa e sustentam as conexões entre universidade e sociedade" (p. 96). Neste conjunto estão: as lacunas de ordem didático-pedagógicas presentes nas práticas de muitos dos docentes do ensino superior, principalmente naqueles que atuam em cursos na área de Ciências Exatas e da Natureza, decorrentes também dos modelos formativos aos quais estiveram submetidos e que tem por base a racionalidade técnica. Alguns pesquisadores indicam que a questão central é que os professores universitários, não só no Brasil, não têm o devido preparo pedagógico para atuarem em atividades de ensino, repetindo em sala o mesmo modelo formativo que receberam em suas graduações (ALMEIDA, 2012; CUNHA, 2006; PIMENTA; ANASTASIOU, 2002). 
- Revista de Iniciação à Docência, v. 5, n. 1, 2020 -

Dossiê Temático: Docência Universitária: contribuições da pesquisa Publicação: maio, 2020 - ISSN 2525-4332

Também, a forma como estes sujeitos se tornaram docentes universitários é complexa. Como bem considera Cortela (2013), geralmente começam a atuar na universidade a partir de um concurso público, muitos sem antes ter ministrado aulas em outros níveis de ensino, aqueles que cursaram a licenciatura provavelmente teriam alguns conhecimentos relativos ao planejamento, abordagens metodológicas e avaliação, por exemplo, tendo feito também o estágio supervisionado; alguns poucos puderam experienciar atividades de ensino durante os estágios docentes, nos cursos de pós-graduação. Assim, ingressam em departamentos e ministram disciplinas pré-estabelecidas, sendo também responsáveis por atividades de pesquisa, extensão e gestão. Na maioria dos casos, não receberam formação anterior para a docência e também não recebem nenhuma orientação institucional no que diz respeito às atividades de ensino que irão desempenhar. E também não são cobrados neste sentido, na maioria dos casos, como o são em relação à pesquisa, por exemplo.

Como afirma Cortela (2013) trazem consigo, além de saberes relativos à pesquisa, um saber específico dos conteúdos que ministram, inúmeras experiências sobre o que é ser professor, decorrentes do longo período de formação como alunos. Construíram para si modelos de bons e de maus professores, nos quais se espelham para reproduzir ou negar ações; têm introjetadas, as agruras da profissão, o desgaste emocional que ela acarreta e os estereótipos socialmente construídos do ser professor.

O perfil profissional do docente universitário vem condicionado por um devir histórico, marcado pelo modelo educativo, institucional, legislativo e social do processo de formação docente (BOZU; HERRERA, 2009, p. 90, tradução das autoras)

Muitos carregam consigo ideias de senso comum ${ }^{10}$ sobre o ser e atuar como professor. Entre elas: que quem sabe, automaticamente, sabe ensinar; que o professor nasce pronto, algo vocacional; e que basta ser um profissional na área para poder ensinar, que ensinar se aprende ensinando, entre outras (MASETTO, 2002).

As concepções anteriormente enunciadas foram legitimadas, muitas vezes, porque eram condições suficientes para o modelo de ensino adotado pela maioria das universidades: centrado no professor, nos conteúdos que ele julgava serem necessários à formação dos alunos, onde aprender, na maioria dos casos, significava repetir nas provas o que o professor havia trabalhado em sala. Mas, atualmente, não mais o são.

O papel do professor universitário está em crise e deve ser totalmente repensado. O papel de transmissor de conhecimento, função desempenhada até quase os dias de hoje, está superado pela própria tecnologia existente. Qual é esse novo papel? (MASETTO, 2002, p. 18).

\footnotetext{
${ }^{10}$ Um conhecimento evidente, prático e pragmático que faz coincidir causa e intenção. No caso do ensino e da atuação docente, é um saber geral e prático, conhecido e introjetado pelos docentes. Permeado por contradições, constitui a matéria prima, a base do conhecimento pedagógico.
} 
- Revista de Iniciação à Docência, v. 5, n. 1, 2020 -

Dossiê Temático: Docência Universitária: contribuições da pesquisa Publicação: maio, 2020 - ISSN 2525-4332

Entre as competências esperadas dos docentes universitários, além do domínio de seu campo de pesquisa e dos conteúdos específicos que ministram, também estão, de acordo com ZABALZA (2005): oferecer informações e explicações compreensíveis, possuir domínio em relação à alfabetização tecnológica e saber utilizar as Tecnologias da Comunicação e Informação como recurso didático; capacidade de gestão em relação às metodologias de ensino, voltadas à aprendizagem; capacidade de relacionar-se com os alunos, acompanhando e os orientando em suas atividades; refletir e investigar sobre o próprio ensino; e implicarse institucionalmente e socialmente.

Vale lembrar que o conceito de competência adquiriu uma polissemia. Consideramos que a Álvarez e Gallego (2006) seja adequada: “[...] um conjunto de conhecimentos, habilidades e atitudes necessário para desempenhar uma dada atividade e a capacidade de mobilizar e aplicar estes conhecimentos em outras situações, para produzir um determinado resultado" (p. 23, tradução das autoras). Ou seja: saber, saber fazer, saber ser e saber estar.

Um espectro muito amplo de atividades, algumas passíveis de serem ensinadas, outras, decorrentes do saber experiencial (GAUTHER et al., 1998), construído ao longo das práticas que empreende e dos investimentos pessoais em relação às condutas que adota. Mais que competências e habilidades (conceitos muito associados ao neobehaviorismo) defendemos a mudança de paradigma proposta por Zabalza (2005): sair de uma docência com foco no ensino para outra, que tenha como foco a aprendizagem, buscando assegurar o direito de aprender.

Compreende-se a profissionalidade como um conjunto de capacidades e saberes desenvolvidos pelos docentes no desempenho de suas funções, em diferentes momentos do seu processo de profissionalização (BRZEZINSKI, 2002): um amálgama de profissionalização e identidade. Sua principal característica é a instabilidade, uma vez que é construída em contextos específicos (institucionais) e de forma progressiva; se constitui a partir de habilidades e valores (pessoais), que se incorporam e se materializam em saberes e nas práticas dos docentes. O reconhecimento destes saberes propicia a construção da identidade do docente, seu perfil profissional e que se reflete também naqueles a quem ensina (CORTELA; NARDI, 2013; CORTELA; NARDI, 2015).

Ferreira (2009) faz uma interessante distinção entre profissionalidade, que se relaciona à identidade docente e aos saberes específicos da profissão, e a profissionalização, que é de natureza político-organizativa e está ligada aos direitos dos trabalhadores da Educação. Compreendemos que ambos são igualmente importantes, mas que o segundo não se realiza sem que o primeiro seja atingido.

Concordando com Garcia et al. (2005), "a identidade não é algo que se possua, mas algo que se desenvolve durante a vida" (p. 112). Identidade esta que "[...] é 
- Revista de Iniciação à Docência, v. 5, n. 1, 2020 -

Dossiê Temático: Docência Universitária: contribuições da pesquisa

Publicação: maio, 2020 - ISSN 2525-4332

epistemológica, ou seja, que reconhece a docência como um campo de conhecimentos específicos [...]" (PIMENTA, In: ALMEIDA, 2012, p. 11); e também profissional. Assim, muitas vezes é preciso desconstruir uma identidade e construir outra, no sentido da profissionalização docente. E este processo passa pela superação da concepção de uma atividade docente como amadora, vocacional, provisória e/ou complementar.

\section{Considerações finais}

Na primeira parte deste artigo afirmamos que a universidade brasileira é fruto de modelos que não se consolidaram plenamente. Por esta razão, ela é considerada um fruto híbrido. Cremos que essa é sua condição. Uma vez entendendo-a assim talvez consigamos imaginá-la para o presente-futuro como algo mais próximo às nossas necessidades baseadas em nossa história singular de povo, de sociedade, de Ciência e de formação universitária. Que universidade desejamos? Que professor precisamos e queremos ser? Que relações e construções sobre o trabalho são necessárias e possíveis? São perguntas que necessitam ser respondidas pela sociedade brasileira, pelas políticas públicas e, em especial, por nós, comunidades de professores, estudantes e servidores para que, de fato, a universidade inove, crie e ajude a dar sentido à democracia como exercício e direito de todos.

Estas reflexões nos levam a pensar sobre os atuais desafios propostos para a docência universitária pública. Cremos que muitos dos docentes do ensino superior, assim como nós, em alguns momentos, se encontram numa encruzilhada, por vezes querendo que as coisas voltem a ser como antes, no sentido de manter a autoridade, o direito de estar sempre certo, usar metodologias e formas de avaliação tradicionais, e ter alunos obedientes e não questionadores destas práticas. Como se antes, estas práticas/contextos fossem melhores. Em nossa ótica eram apenas diferentes e possíveis aos contextos em que estavam inseridas, ao público-alvo que atingiam, aos interesses a que se prestavam, refutando a ideia de um comportamento estático, pois a universidade, assim como a sociedade, se renova, se movimenta e se transforma.

Evidenciamos que no atual contexto universitário, a qualidade do trabalho docente passa, não somente por condições físicas de trabalho e salários adequados. Demanda a necessidade de as instituições de ensino superior, em especial, as universidades públicas, encontrem formas de valorizar as atividades de ensino e orientação que os docentes realizam; propiciar momentos e espaços para que ocorram formações pedagógicas em serviço, colaborativa entre os pares; diminuir o excesso de atividades burocráticas que são chamados a executar; estabelecer instrumentos de avaliação de desempenho, se necessário, mas que contemplem, de modo igualitário, todas as diferentes atividades que este profissional desempenha, não somente a produção de novos conhecimentos. Que se construa uma relação identitária da docência universitária como profissão e trabalho que, por sua vez, não 
- Revista de Iniciação à Docência, v. 5, n. 1, 2020 -

Dossiê Temático: Docência Universitária: contribuições da pesquisa Publicação: maio, 2020 - ISSN 2525-4332

pode ser realizado sem uma socialização entre grupos e a partir de distinções entre outras categorias.

Quanto a nós, docentes, cabe repensar nossas práticas tendo como perspectiva o profissional que pretendemos formar, a sociedade que almejamos construir, o ser social que desejamos que seja parte integrante e estruturante de uma sociedade mais justa e democrática.

Se no começo do texto colocamos um trecho de uma fala do Coelho de Alice no país das Maravilhas (1865) que diz: Meu deus, meu deus!!! Como estou atrasado!” fazendo alusão ao tempo como um dispositivo de não pararmos diante da vida e de nossas escolhas, ele também nos afirma que "a única forma de chegar ao impossível é acreditar que é possível" e isso nos enche de esperança. Assim continuaremos na defesa de nosso trabalho e olhando para o horizonte das discussões sobre a docência universitária como apenas o começo de uma longa jornada em que o tempo de produção do conhecimento não deve ser alienado ao modo de produção capitalista.

\section{Referências}

ALARCÃO, I. Profissionalização docente. In: II Congresso Internacional sobre Formação de Professores nos Países de língua e Expressão Portuguesa. 1998. Anais.... p. 100-118.

ALMEIDA, M. I. Formação do professor do ensino superior: desafios e políticas institucionais. São Paulo/SP: Cortez, 2012.

ARAÚJO, C. V. B.; SILVA, V. N.; DURÃES, S. J. Processo de Bolonha e mudanças curriculares na educação superior: para que competências? Educação e Pesquisa, v. 44, 2018, p. 1-17.

ÁLVAREZ, Y. C.; GALLEGO, L. V. Planificar desde competencias para promover el aprendizaje. El reto de la sociedad del conocimiento para el profesorado universitario. Bilbao, España: Universidad de Deusto, 2006.

BRASIL. Instituto Nacional de Estudos e Pesquisas Educacionais Anísio Teixeira (Inep). Censo da Educação Superior 2018: notas estatísticas. Brasília/DF, 2019.

BRASIL. Instituto Nacional de Estudos e Pesquisas Educacionais Anísio Teixeira (Inep). Censo da Educação Superior 2018: divulgação de resultados. Brasília/DF, 2019.

BRZEZINSKI, I. (Org.). Profissão professor: identidade e profissionalização docente. Brasília/DF: Plano Editora, 2002.

BRITO, T. T. R. A docência no Instituto de Biologia da Universidade Federal de Uberlândia: percorrendo caminhos e encontrando representações. 2006. 216f. Dissertação (Mestrado em Educação). Faculdade de Educação da Universidade Federal de Uberlândia, Uberlândia/MG. 2006. 
- Revista de Iniciação à Docência, v. 5, n. 1, 2020 -

Dossiê Temático: Docência Universitária: contribuições da pesquisa Publicação: maio, 2020 - ISSN 2525-4332

BOZU, Z.; HERRERA, P. J. C. El profesorado universitario en la sociedad del conocimiento: competencias profesionales docentes. Revista de Formación Educativa Universitaria. España, v. 2, n. 2, p. 87-97, 2009.

CARROLL, L. Alice no País das Maravilhas (1865). Rio de Janeiro/RJ: Zahar, 2010.

CASTANHO, S. E. M. A universidade entre o sim, o não e o talvez. In VEIGA, I. P. A.; CASTANHO, M. E. L. M. (Org.). Pedagogia universitária: a aula em foco. Campinas/SP: Papirus, 2000.

CORTELA, B. S. C. Professor universitário: o desafio da construção de uma identidade profissional. In: SILVA, L. F.; DIAS, M.; MANZONI, R. M. (Orgs.) Cadernos de docência da Educação Básica. São Paulo/SP: Cultura Acadêmica, 2013, p. 9-28.

CORTELA, B. S. C.; NARDI, R. A Docência no ensino superior na área de Ciências da Natureza: uma amostra do que dizem as pesquisas nos últimos dez anos. Atas ... II Simpósio Internacional sobre Desenvolvimento Profissional Docente e II Seminário de Temas Pedagógicos, 2015, Curitiba/PR. Rede de Aprendizagem em Foco, 2015b. p. 1-17.

CUNHA, M. I. Pedagogia universitária: energias emancipadoras em tempos liberais. Araraquara/SP: Junqueira \& Marin, 2006.

. O professor universitário na transição de paradigmas. Araraquara/SP: Junqueira \& Martins, 1998.

CUNHA, L. A; GOES, M. O golpe na Educação. Rio de Janeiro/RJ: Jorge Zahar, 2002.

DELIZOICOV NETO, D. Docência no ensino superior e a potencialização da pesquisa em educação em ciências. In: GARCIA, N. M. D. [et al.]. A pesquisa em ensino de Física e a sala de aula: articulações necessárias. São Paulo/SP, Editora da SBF, 2010, p. 227-238.

FÁVERO, M. L. Universidade e poder. Brasília/DF: Plano, 2000. 260 p.

FERREIRA, M. O. V. Discutir a educação é discutir o trabalho docente: o trabalho docente segundo dirigentes da Confederación de Tabajadores de la Educacíon de la República Argentina. Revista Brasileira de Educação. Rio de Janeiro, v. 14, n. 41, p. 281-295. Maio/ago. 2009.

GARCIA, C. M. A identidade docente: constantes e desafios. Revista Brasileira de Pesquisa sobre Formação Docente. Belo Horizonte/MG, v. 1, 2009, p. 109-131.

GARCIA, M. M. A; HYPOLITO, A. M; JARBAS, S. V. As identidades docentes como fabricação da docência. Educação e Pesquisa. São Paulo, v.31, n.1, p. 45-56, jan/abr. 2005.

GAUTHIER, C. et al. Por uma teoria da pedagogia: pesquisas contemporâneas sobre o saber docente. Ijuí/RS: Editora UNIJUÍ, 1998. (Coleção Fronteiras da educação).

MASETTO, C. (Org.). Docência na universidade. Campinas /SP: Papirus, 2002. 
- Revista de Iniciação à Docência, v. 5, n. 1, 2020 -

Dossiê Temático: Docência Universitária: contribuições da pesquisa Publicação: maio, 2020 - ISSN 2525-4332

NOVOA, A. (Org.). Os professores e a sua formação. Lisboa: Dom Quixote, 1992b.

PAULA, M. de F. C. de. USP e UFRJ a influência das concepções alemã e francesa em suas fundações. Tempo Social: Rev. Sociol. USP. v. 14, n. 2, 2002, p. 147-161.

PIMENTA, L. A; ANASTASIOU, L. G. C. Docência no ensino superior. São Paulo, Cortez, 2002.

PIMENTA, S. G.; GHEDIN, E. (Org.). Professor reflexivo no Brasil: gênese e crítica de um conceito. São Paulo/SP: Cortez, 2006.

SOUZA, J. A. et al. Concepções de universidade no Brasil: uma análise a partir da missão das universidades públicas federais brasileiras e dos modelos de universidade. Revista GUAL, Florianópolis/SC, v. 6, n. 4, 2013, p. 216-23. Edição Especial. 2013.

SILVEIRA, Z. S.; BIACHETTI, L. Universidade moderna: dos interesses do Estadonação às conveniências do mercado. Revista Brasileira de Educação, v. 21, n. 64, 2016, p. 79-99.

SGUISSARDI, V.; SILVA JÚNIOR, J. R. Trabalho intensificado nas federais: pósgraduação e produtivismo acadêmico. São Paulo/SP: Xamã, 2009.

TEIXEIRA, A. Educação no Brasil. 3. ed. Rio de Janeiro/RJ: UFRJ, 1999.

TARDIF, M. Saberes docentes e formação profissional. Petrópolis/RJ: Vozes, 2002.

ZABALZA, M. A. Competências docentes. Conferência. Universidade Javeriana de Cali, 09 de fev. 2005. 